\title{
IMPLEMENTATION OF A PULL SYSTEM - A CASE STUDY OF A POLYMERIC PRODUCTION SYSTEM FOR THE AUTOMOTIVE INDUSTRY
}

\author{
Bruna MARTINS, Cláudia SILVA, Diogo SILVA, Laura MACHADO, Miguel BRÁS, \\ Rui OLIVEIRA, Tiago CARVALHO, Vera SILVA, Rui M. LIMA \\ University of Minho
}

\begin{abstract}
:
This work, developed as a case study, propose, describe, and evaluates an implementation of a pull system in a SME company producing polymeric components for the automotive industry. The production system of the company was based on the push paradigm, which creates high stock levels and high lead times. The main purpose was to develop a pull production system controlled by Kanbans in the painting line. To achieve this goal, this case study demonstrates the application of relevant lean tools, such as, VSM, SMED, Kanban System, Supermarkets and Leveling. Through the SMED's application, it was possible to reduce the setup times in $38 \%$ and make annual earnings of approximately $83000 €$. The application of a Kanban System, Leveling and Supermarket enabled the WIP's reduction between injection and painting in $56 \%$ and, also, between painting and expedition in $45 \%$. Also, the lead time decreased and the value-added time increased. Thus, this is an exemplary case study for the implementation of a pull system and can be used both by practitioners and researchers interested in this theme.
\end{abstract}

Key words: Kanban, Leveling, Pull Production, SMED, Supermarket

\section{INTRODUCTION}

In order to respond to the increasing competition forced by the market, companies must improve their ability to adjust their production systems through the introduction of new paradigms. The Pull Production System's implementation involves other Lean Production tools application, such as, Single Minute Exchange of Die (SMED), Kanban Systems, Leveling and Supermarkets [1]. Several works $[2,3,4]$ were devoted to the analysis of specific approaches to design a pull system, but it is not common to find works focusing on different steps that a company must carry out to create the conditions to implement a pull system. Studying and researching ways that would help to overcome this gap is even more important as a pull system was found to be one of the supportive elements of Lean in the world of Industry 4.0 [5].

This works tries to make a contribution to the literature demonstrating a set of integrated steps that may support a company to be prepared to the implementation of the pull system. Thus, this work aims proposing, describing and evaluating an implementation of a pull system in a polymeric components company for the automotive industry. The company where the project was developed has the purpose of reducing its Work-In-Process (WIP) levels and the non-value-added activities.

After the introduction, the structure of the present article continues with the literature review. Then, a productive system's description is made, followed by a critical analysis. The fourth section present the steps developed for implementation of the pull system. Finally, the article ends with the discussion and conclusions.

\section{LITERATURE REVIEW}

Lean Production has the principal purpose of increasing the earnings through the costs' reduction, through the removal of wastes $[6,7,8,9]$. This way, Lean production focus on delivering value with high quality and fewer defects in comparison to traditional manufacturing systems such as mass production systems [10]. Lean success depends on recognizing what is considered as 'of value' by the customers. This, therefore, needs to be established from the outset and will guarantee that Small and Medium-Sized Enterprises (SMEs) can direct the Lean process towards a concise comprehension of what the customer values [11]. Moreover, and ultimately important to Lean principles is the respect for the human condition of operators [12] and 
the recognition of the importance of teams for Lean success [4].

Being the creation of flow in the production system, a fundamental goal of lean [13], in order to achieve an efficient Pull Production System's implementation, the problems of the current production system must be analyzed. To do that, Value Stream Mapping (VSM) tool is the most common tool referred in the literature [14]. A Value Stream encompasses all the activities, both value-added, and non-value added, currently required to bring a product through the material and information flows. The process of creating the mapping is developed following a product's production path from costumer to supplier, and carefully drawing a visual representation of every process in the material and information flow [15]. A VSM allows to visualize the progressive work being developed, aiming at highlighting some of the main wastes in the production system. It provides a pictorial view of existing process and provides guides to identify gap areas for improvement through the application of Lean concepts and tools [16]. The mapping should support to create suggestions based on economic feasibility and ease of implementation, and thus should lead to a feasible future-state VSM [17] that will become the roadmap to achieve a continuous flow system. Such a flow system is achieved by the establishment of a Lean-pull production strategy [16].

A Pull System allows to create a Just-in-Time (JIT) production system because it creates a system where each supplier (internal or external) serves the quantity demanded by each client (internal or external), reducing stocks and wastes related to the productive process, as well as reducing the lead times and ensuring the client's satisfaction. If a firm is interested in improving productivity, should be focusing on introducing a Pull System [15]. In such a production system, each process inside the company acts as an internal client, which should receive the product in the correct quantity and time [18]. In order to inform all processes about necessary timing and quantity of production parts, the pull system uses Kanbans [3]. Since the pull production system engages in small-lot production, frequent transport, and frequent delivery, therefore, delivery and receiving locations and parts must be written explicitly in the Kanban, in order to maintain and coordinate the discipline in the pull system [6]. Therefore, a Kanban System is a visual control system where the orders are automatically transformed in authorizations through a Kanban card. These cards must be organized by its priorities and put in a Production Planning Board [19]. The number of Kanbans in a given loop will therefore depend upon demand and, if demand changes, then the number of Kanbans can be adjusted accordingly [20].

A supermarket allows a simple management process of parts. This is a major element in the pull production planning. A supermarket is a storage area that works with predefined rules, such as, having a fixed location for every part number, providing easy picking access, allowing visual management, keeping the FIFO principle and easy handling of small containers/rollers/trolleys [1]. Besides, a supermarket is a system that allows controlling the stock excess because the super-market stock is based on the client's demand [21]. Production leveling is one of the pillars of the Toyota Production System [22]. Since timing and volume are critical, production processes are arranged to facilitate production of the required quantity at the required time, and worker, equipment, and all other factors are organized toward that end.

As discussed by Chiarini [23] many companies strive to balance lot sizes with setup times, to ensure a good performance of a pull production system. Thus, it is necessary to reduce the setup times, and, for that, the SMED tool makes it possible to respond quickly to fluctuation in demand, and creates the necessary conditions for lead time reductions [24]. In summary, the reduction in manufacturing lead time requires concentrating on understanding customer needs, introducing pull system, focusing on setup time reduction [15].

\section{METHODOLOGY OF THE RESEARCH}

As this work aims proposing, describing, and evaluating an implementation of a pull system in a polymeric components company for the automotive industry, a case study will be developed. A case study allows to understand in a deep way a concrete and real research subject. In this way, this work will contribute, both for researchers and practitioners, to get a grasp on the steps involved to implement a pull production system in a SME company developing polymeric components for the automotive industry.

In order to apply the case study methodology, it is important to describe in detail the context of the study. The current state of the relevant part of the company's production system is going to be analyzed.

This company produces cars plastic parts. There are three production sections: injection, painting and assembly. The relevant production system for this project, manages eleven product references, in which seven go through the path Injection - Painting and the remaining four go through the path Injection - Painting-Assembly.

The injection's machines have large setup times, which leads the company to have a "Batch Production" to avoid the constant changes of the references, that leads to a high level of WIP in the injection's supermarket. Following this, the products go to the Painting machine to be painted. After that, part of the items goes to the finished products' warehouse to be shipped and other part of the items goes to the assembly section before going to the warehouse.

When the order arrives, the logistics department sends the information to the different production sections and the production starts in a push environment, where the production is pushed through the different sections in the order mentioned before.

\section{Critical analysis}

The first step of analysis was the calculation of the takt time of each product, considering that the amount of available time was equal to the shift of production of the 
last process. It was necessary to do such an approach because the three production sections have a different number of shifts. When comparing the takt-time of the products with their respective cycle time it was concluded that it is very low. Therefore, the company has enough available capacity considering the usual demand.

Furthermore, in order to analyze the current production system, it was developed a Value Stream Mapping (VSM) considering the product with the higher demand.

This product was chosen because it has the higher influence in the entire production system. This VSM was developed in the shop floor where all the details were seen and evaluated. So, the final result is shown in Figure 1 where only the most important part of the VSM is shown.

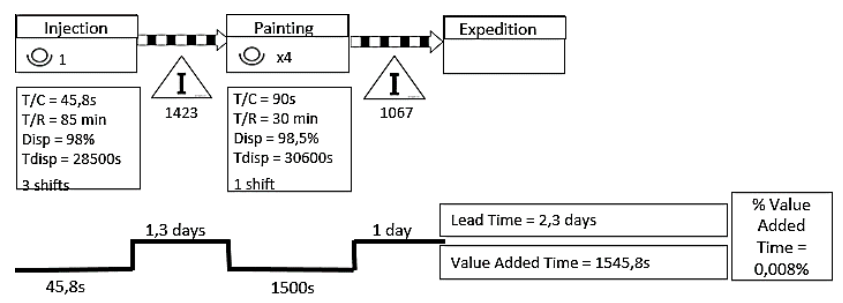

Fig. 1 Current State VSM

Analyzing the current system, it was concluded that the lead time of the product is very high when comparing it to the time where value added activities are being held. This is caused by the time that the product waits on the injection's supermarket to go to the next operation. So, it was concluded that only in $0.78 \%$ of the time is being added value to the product.

It is also possible to see that the machine's preparation time is very high, which leads to a batch-based production in order to minimize the effect of the time lost on setups. As seen in the picture, this leads to an excessive amount of WIP between sections, occupying an exaggerated amount of space.

Summing up, the problems detected on the company were: the large amount of time that products wait on the supermarket, an over production and a high travel time for each product.

\section{Steps for the implementation of the pull system}

According to Total Flow Management methodology the main steps for pull production implementation are reducing changeover times, production leveling, Kanban system implementation and finally the implementation of supermarkets [1]. So, it was decided that the first step would be reducing changeover times using Single Minute Exchange of Die (SMED) in order to be able to level the production in smaller cycles decreasing the production batch. Then, it was possible to develop a production leveling proposal, followed by a Kanban system and supermarkets to ensure that this system works properly.

\section{RESULTS OF RESEARCH}

This section describes the main results of the developed case study, regarding the implementation of a pull system.

\section{Single Minute Exchange of Die}

Currently, the injection machine's setup times are an obstacle to the pull production system's implementation, since they are very high. To overcome this problem, SMED was selected, because it can be applied to any equipment or workstation that loses time or efficiency when changing from one product to another [1]. In order to apply SMED, a mold's changeover was observed in one of the injection machines. Then, the SMED was applied based on the following steps [1]:

1. Current State Analysis. The setup's study started with the detailed annotation of all activities that were being made and their duration. The total time of all activities was 1 hour, 25 minutes and 51 seconds.

2. Classification of internal versus external activities. Internal activities are those that can be done only with the machine stopped. External activities are those that can be done while the machine is operating.

3. Converting internal activities to external. In this step, a detailed analysis of the internal activities was done. Some of these activities were identified as being potential candidates to be done externally to the changeover. The total time of these activities that could be done with the machine working was 19 minutes and 22 seconds.

4. Internal work's reduction. After converting internal to external activities, it is necessary to reduce the total duration of internal activities. To do that, a precedence network [25] was developed, identifying the tasks that can be done in parallel, which could be executed by more than one setup collaborator. This option was considered practicable since, usually, an operator is responsible for more than one machine, this way, when one of them is in preparation mode, his occupancy rate is always less than $100 \%$.

5. External activities time reduction. In terms of external work, there is the possibility of reducing the time of the mold's transport next to the injection machine. Currently, some of the mold are stored 73.79 meters away from the machine.

\section{Leveling}

After the changeover times were lowered, it was relevant to level the production. The product demand is very stable, so it was possible to have an idea of the weekly demand for each product. Then, it is important to note that the company has deliveries on Tuesday and on Friday, where they have to hand out $40 \%$ of the week's demand and $60 \%$ of the week's demand, respectively. In order to level the production, and in this way allowing the production line to have more flexibility, it was decided in accordance with the company to define two different production cycles, one starting on Tuesday and ending on Thursday and the other one starting on Friday and ending on Monday. Thus, the company would produce $60 \%$ of its demand on each cycle ( $20 \%$ more than its weekly demand) to prevent stock breaks and respond to little demand variations with an additional stock. 
As the injection process takes some time to reach a certain stability, it was decided to define one cycle of production for each part of the week, avoiding to change over a machine more times per week. So, in each cycle, firstly the class A products should be produced, then the class $B$ products and lastly the class $\mathrm{C}$ products.

\section{Kanban System}

The company already stores the products in boxes throughout their production system. As this box can store multiple products and are easily transported it was decided that this box would represent the Kanban container. This system will allow the company to produce only when its necessary. For each production cycle it is pre-established the number of Kanbans based on the clients' demand. Thus, it is possible to avoid over-production, leading to the decrease of WIP, the major problem in the company's production system.

The Kanban-card method involves the use of a Kanbancard containing information of an individual work item to travel together with the inventory [26]. That card will describe the product transported in the box, with information about his name, the quantity, the lead-time, among others, as shown in Figure 2.

\begin{tabular}{|c|c|c|c|}
\hline \multicolumn{2}{|l|}{ Description } & \multicolumn{1}{c|}{ Item Nr. } \\
\hline \multicolumn{2}{|l|}{ Product Name } & \multicolumn{2}{|c|}{ P123.45.67.8.9 } \\
\hline Qty. & 64 & $\begin{array}{c}\text { Lead } \\
\text { Time }\end{array}$ & $\begin{array}{c}3 \\
\text { days }\end{array}$ \\
\hline $\begin{array}{c}\text { Order } \\
\text { Date }\end{array}$ & \multicolumn{3}{|c|}{$02 / 10 / 2021$} \\
\hline $\begin{array}{c}\text { Due } \\
\text { Date }\end{array}$ & \multicolumn{3}{|c|}{$05 / 10 / 2021$} \\
\hline \multicolumn{4}{|c|}{ Card 2 of 30 } \\
\hline Project & AB123 & Loc. & Sl.05-2 \\
\hline \multicolumn{4}{|c|||||||||||||||||||||||||}{} \\
\hline
\end{tabular}

\section{Fig. 2 Kanban card}

This card is important to secure the boxes flow designed on the proposed system and to know the location of a product in the company.

In this transition phase (push-pull), it was considered the time that the company had between the moment they start producing until the moment they have to deliver their products, which is referred as lead-time. As mentioned before, it was defined that there would be two production cycles where in each cycle, it is produced $60 \%$ of the demand. So, it was obtained a lead-time of 2.33 days, once the company starts producing on Friday and has to deliver on Tuesday, and a lead-time of 3 days once the company starts producing on Tuesday and has to deliver on Friday. As for the security-factor it was defined that it should be $10 \%$ on an initial phase because the company is not used to operate in such a system. Finally, the container's capacity is equal to the capacity of the respective box that is used currently for storing the product by the company. It is important to note that each type of product has its box and its own capacity.

So, the expression that was used is represented below (1) and it is adapted from Sugimori's equation for the number of Kanbans calculation [12].

$$
\text { Kanbans } \mathrm{Nr}=\frac{\text { Demand } \times \text { Lead Time } \times(1+\text { Security Factor })}{\text { Container Capacity }}
$$

By using this expression, and the demand provided by the company the number of Kanbans was obtained for each production cycle, and for each product. On the first production cycle ( 2.33 days) it was calculated 140 Kanbans for the injection section and 144 Kanbans for the painting process. On the second production cycle (3 days) it was calculated 179 Kanbans for the injection section and 183 Kanbans for the painting section.

Firstly, the cards will start in the final workstation (Painting) and move in materials' opposite direction. This way it is possible to pull the production according to the customer's will, using two Kanban's cycles:

- One cycle between the warehouse and the painting workstation.

- Another cycle between the painting workstation and the injection section.

This way, each section receives empty boxes with the corresponding Kanban card, giving the authorization to produce the quantity mentioned in the card. As mentioned, the cards have to move backwards in the production system, so this empty boxes always come from the forward workstation. For example, the Painting workstation will receive empty boxes that come from the final warehouse. The attachment of cards to the WIP inventory is vital, being the three options for card attachments to be attached (1) to the panels, inserted as (2) part of the job card, or on (3) material transfer [3]. When the empty box arrives in the right workstation, the attached card is moved to a board, allowing the workers to have visual control of what is needed to produce in order to fill the box.

After producing what is needed, the Kanban card is moved again and attached to the box, indicating the product that it carries. This full box is ready to be moved forward. For example, the products that come out of the injection workstations have to be moved to the injection's supermarket to fuel the painting machine.

According to this, the Kanban Flow in each section is represented in Figure 3.

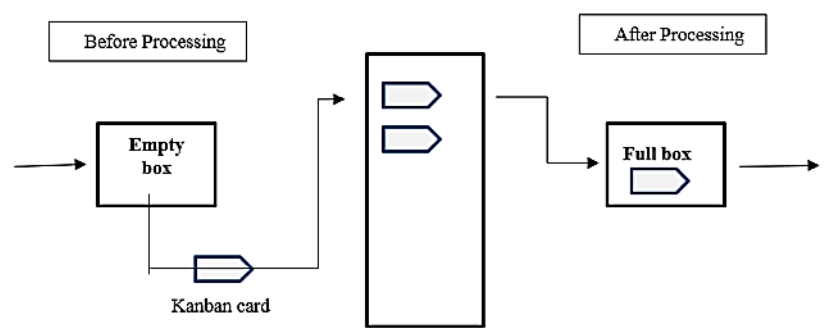

Fig. 3 Kanban Flow in every workstation 
Once calculated the number of Kanbans per section, it is fundamental to verify if the company has capacity to produce what was defined. So, it was developed a Capacity Analysis Chart based on the total available production time of each machine, and the time needed to produce the quantity purposed.

As shown in Figure 4 the company has capacity to produce the number of Kanbans calculated previously. With orange color it is represented the total available production time for the 1st cycle and in blue the time needed to produce the quantity ordered. With green is represented the available production time for the second cycle and with yellow the time needed to produce the quantity ordered to the 2 nd cycle.

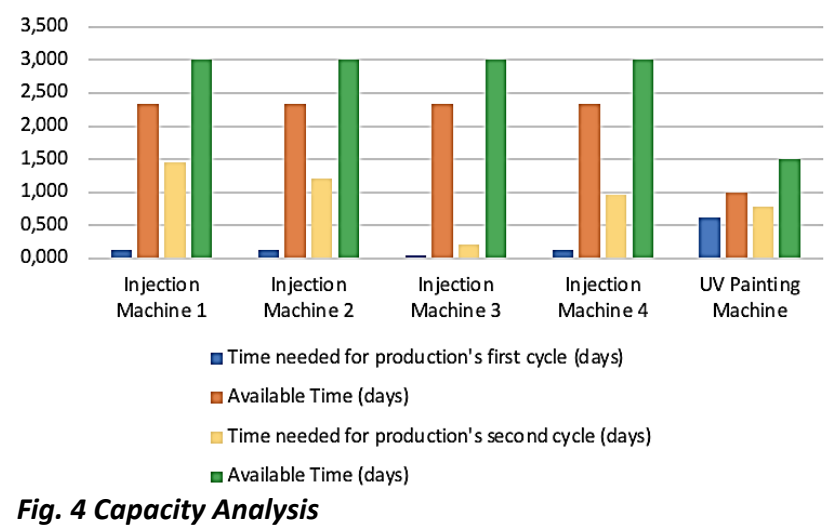

\section{Supermarkets}

The pull system of this project includes intermediate product supermarkets, whose size was calculated considering a maximum and minimum heights of the racks respecting ergonomic conditions to the logistic operators' health and wellbeing. In a pull system, the system aims for a minimum inventory while maintaining an effective management of materials flow [26], so the intermediate products supermarkets are important to support such an effective flow of materials.

The storage system chosen for the supermarkets proposed was the flow rack, which allows the rotation of boxes by FIFO rule and an easier access to them, with one side of the rack for loading boxes and the other one for unloading.

To respect the ergonomic conditions mentioned above, the boxes must be handled between the height of the knees and the shoulders, so the maximum height of the racks is $1022 \mathrm{~mm}$ and the minimum height is $336 \mathrm{~mm}$ which means that supermarkets can only have two levels bearing in mind that all the boxes used in this project have a dimension of $600 \cdot 400 \cdot 280 \mathrm{~mm}$ (length $\cdot$ width.height). It was considered that the height of the inclination is $100 \mathrm{~mm}$. Figure 5 illustrates the proposed solution for product supermarkets.

Considering the maximum number of Kanbans per product, the maximum number of boxes that could be present in each supermarket was calculated. For each reference it was considered a capacity gap of $10 \%$.

In the supermarket between the injection and the painting, the maximum number of boxes is 179 . After this, it was considered a racks' depth of $3200 \mathrm{~mm}$, corresponding the space needed for eight boxes.

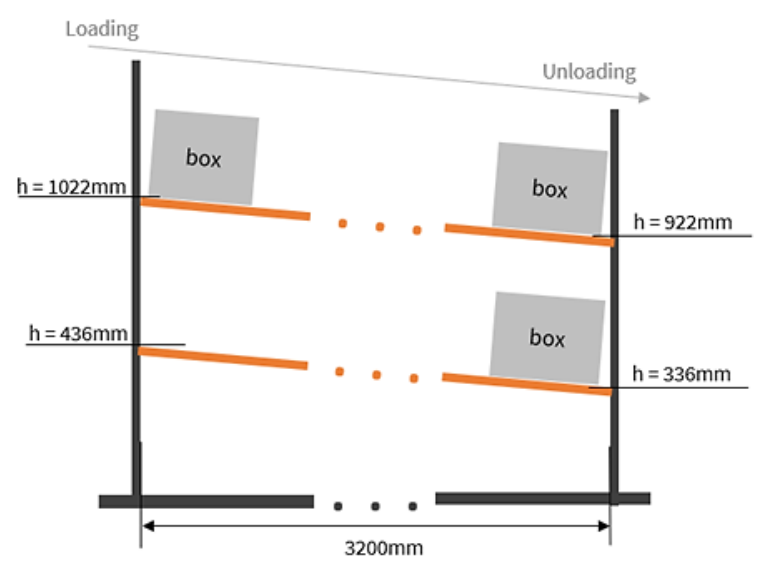

Fig. 5 Supermarkets' racks representation

After dimensioning the supermarket, it was necessary to define the location of each product. It is important to refer that the products will have a fixed location and the products whose number of Kanbans is higher will be located closest to the next workstation while those with lower number of Kanbans will be further away. In each supermarket's rack, there will be a label identifying the product to be placed on that location and the label color will differ according to the product.

Figure 6 represents the locations of the products in the supermarket between injection and painting, as well as the different colors for each product.

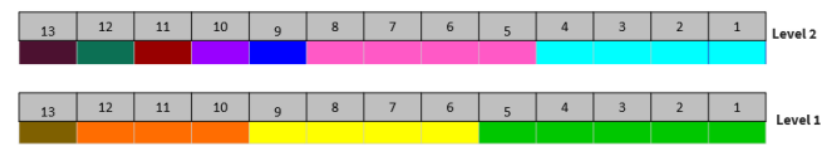

Fig. 6 Representation of products' locations in a supermarket between injection and painting workplaces

\section{DISCUSSION}

In this section, the results obtained are analyzed and compared to the initial state. The SMED's implementation was very efficient in terms of mold changeover time reduction. This way, it was possible to obtain a reduction comparing to its initial time of around $38 \%$, so the setup decreased to 52 minutes and 58 seconds. This leads to an increase of the machines' working time to 32 minutes and 53 seconds by shift, just by planning the tasks and using two operators instead of one.

In terms of the travelled distance to pick up the new mold, it was possible to reduce it around 68\% in case the mold's storage was in the injection's section, since there is space available to do that.

These proposals allowed the company to have annual earnings of approximately $83000 €$. Furthermore, the investment would have its return in the same month that the SMED is implemented because of the productive time gained. 
The proposed size for the supermarkets has a satisfactory value in terms of the space occupied by the racks versus the space available.

In order to analyze the obtained results, the future VSM was developed based on a simulation in SIMIO software represented in Figure 7. In the VSM were represented the material and information flows through supermarkets and Kanban Systems. Implementing pull production, it is possible to reduce the WIP between injection and painting by $56 \%$ and, between painting and expedition by $45 \%$. The lead time reduces, and the value-added time increases.

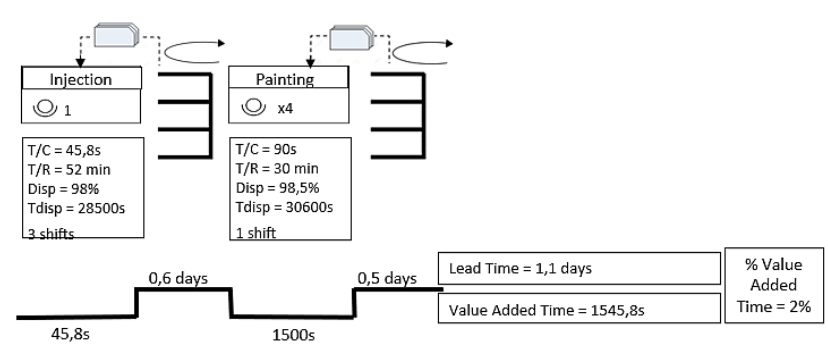

Fig. 7 Future State VSM

\section{CONCLUSIONS}

The proposed solution of the pull system implementation has demonstrated through the future VSM, a significant reduction in WIP and lead time. Although the pull system is one of the simplest production control systems, this solution requires a company to overcome some difficulties, the main one is the high machine setups that prevent leveling the production with lower production batches.

The application of the SMED tool on one of the injection machines led to a significant reduction in setup times (about half the time), which results in major gains in the short term, not only in monetary but also in production areas.

The proposal of a production control system based on Kanban cards has as the main purpose to authorize or not the production of a certain product. To support the material and information flows, a board to allow visual control of Kanbans is required. Additionally, the definition of supermarkets between each production areas, which were sized considering the maximum space required and the appropriate ergonomic conditions to the logistics operator, allows to create the conditions for a smooth flow of materials.

As work to be developed in the near future, alongside the implementation of the pull system, it will be necessary to train and communicate to workers the benefits of this change and most important to listen to their ideas of improvement to maximize their involvement and motivation.

Due to time limitations, this case study did not allow to analyze human factors related to changing working methods.

It is also recommended to invest in continuous improvement and in the application of Lean principles and techniques, which can support and foresee great progress in this phase of the company's growth.

\section{ACKNOWLEDGMENTS}

This work has been supported by FCT - Fundação para a Ciência e Tecnologia within the R\&D Units Project Scope: UIDB/00319/2020.

\section{REFERENCES}

[1] E.A. Coimbra, Total Flow Management: Achieving Excellence with Kaizen and Lean Supply Chains, 2009.

[2] J.C. Lu, T. Yang and C.Y. Wang, "A lean pull system design analysed by value stream mapping and multiple criteria decision-making method under demand uncertainty," International Journal of Computer Integrated Manufacturing, vol. 24, no. 3, pp. 211-228, 2011.

[3] J. Prakash and J.F. Chin, "Implementation of hybrid parallel kanban-CONWIP system: A case study," Cogent Engineering, vol. 1, no. 1, p. 938922, 2014.

[4] K. Grant and C. Hallam, "Team performance in a lean manufacturing operation: It takes the will and a way to succeed," International Journal of Technology Management, vol. 70, no. 2-3, pp. 177-192, 2016.

[5] R. Saxby, M. Cano-Kourouklis and E. Viza, "An initial assessment of Lean Management methods for Industry 4.0," TQM Journal, vol. 32, no. 4, pp. 587-601, 2020.

[6] Y. Monden, Toyota Production System: An Integrated Approach to Just-In-Time, 1998.

[7] M. Ghosh, "Lean manufacturing performance in Indian manufacturing plants," Journal of Manufacturing Technology Management, vol. 24, pp. 113-122, 2013.

[8] R.M. Lima, J. Dinis-Carvalho, T.A. Souza, E. Vieira and B. Gonçalves, "Implementation of Lean in Healthcare environments: an update of systematic reviews," International Journal of Lean Six Sigma, 2020.

[9] A.A. Neto, R.M. Lima, P. Afonso and N.T. d. Silva, "Analysis of the Adoption of Lean Practices in Brazilian Companies: an Exploratory Study," Sistemas \& Gestão, vol. 13, no. 2, pp. 196-208, 2018.

[10] G. Narayanamurthy and A. Gurumurthy, "Is the hospital lean? A matematical model for assessing the implementation of lean thinking in healthcare institutions," Operations Research for Health Care, vol. 18, no. , pp. 84-98, 2018.

[11] A. Alkhoraif, H. Rashid and P. McLaughlin, "Lean implementation in small and medium enterprises: Literature review," Operations Research Perspectives, vol. 6, p. 100089, 2019.

[12] Y. Sugimori, K. Kusunoki, F. Cho and S. Uchikawa, "Toyota Production System and Kanban System - Materialization of just-in-time and respect-for-human system," International Journal of Production Research, 1977.

[13] J. Bassuk and I. Washington, "Iterative development of visual control systems in a research vivarium," PLOS ONE, vol. 9, no. 4, p. e90076, 2014.

[14] E. Sordan Juliano, C. Oprime Pedro, L. Pimenta Márcio and L.F. Chiabert P., "Lean Six Sigma in manufacturing process: a bibliometric study and research agenda," The TQM Journal, 32(3), pp. 381-399, 2020.

[15] M. Rother and J. Shook, Learning to See: value stream mapping to add value and eliminate muda, 1999.

[16] S. Kumar, A. Dhingra and B. Singh, "Lean-Kaizen implementation: A roadmap for identifying continuous improvement opportunities in Indian small and medium sized enterprise," Journal of Engineering, Design and Technology, vol. 16, no. 1, p. 5, 2018. 
[17] V. A. Raghavan, S. Yoon and K. Srihari, "Lean transformation in a high mix low volume electronics assembly environment," International Journal of Lean Six Sigma, vol. 5, no. 4, pp. 342-360, 2014.

[18] A.S.B. d. Araújo, "Implementação de um Sistema Pull e outras Técnicas de Produção Lean numa Linha de Montagem de Componentes Eletrónicos," 2011.

[19] A. Alves, G. Rocha and F. Braga, "Implementação de um Sistema Pull numa Linha de Montagem de Componentes Eletrónicos," 2011.

[20] J. Darlington, M. Francis, P. Found and A. Thomas, "Design and implementation of a Drum-Buffer-Rope pull-system," Production Planning \& Control, vol. 26, no. 6, pp. 489-504, 2015.

[21] P. Pereira, "Melhoria dos Processos de Secção de Corte através da aplicação de ferramentas Lean Production numa Empresa de Componentes para a Indústria Automóvel," 2020.

\section{Bruna Martins}

University of Minho

School of Engineering, Centro Algoritmi

Department of Production and Systems

Campus Azurem, 4800-058 Guimaraes, Portugal

e-mail: bruna.alex.martins@hotmail.com

\section{Cláudia Silva}

University of Minho

School of Engineering, Centro Algoritmi

Department of Production and Systems

Campus Azurem, 4800-058 Guimaraes, Portugal

e-mail: claudia2903silva@gmail.com

Diogo Silva (correspondent autor)

University of Minho

School of Engineering, Centro Algoritmi

Department of Production and Systems

Campus Azurem, 4800-058 Guimaraes, Portugal

e-mail: diogoscb21@gmail.com

\section{Laura Machado}

University of Minho

School of Engineering, Centro Algoritmi

Department of Production and Systems

Campus Azurem, 4800-058 Guimaraes, Portugal

e-mail: laurapnhmachado@gmail.com

\section{Miguel Brás}

University of Minho

School of Engineering, Centro Algoritmi

Department of Production and Systems

Campus Azurem, 4800-058 Guimaraes, Portugal

e-mail: miguel.atf.bras@gmail.com

\section{Rui Oliveira}

University of Minho

School of Engineering, Centro Algoritmi

Department of Production and Systems

Campus Azurem, 4800-058 Guimaraes, Portugal

e-mail: rucaalex@hotmail.com
[22] S. Shingo, A Study of the Toyota Production System, 1989.

[23] A. Chiarini, "An adaptation of the EOQ formula for JIT quasi-pull system production," Production Planning \& Control, vol. 28, no. 2, pp. 123-130, 2017.

[24] S. Shingo, A Revolution in Manufacturing: The SMED System, 1983.

[25] R.M. Sousa, R.M. Lima, D. Carvalho and A. Alves, "An Industrial Application of Resource Constrained Scheduling for Quick Changeover," in IEEE International Conference on Industrial Engineering and Engineering Management, Hong Kong, 2009.

[26] N. Shaardan, E. Roslin and M. Ahamat, "Lean management concept in energy efficiency improvement for nondomestic," International Journal of Applied Engineering Research, vol. 12, no. 4, pp. 15242-15251, 2017.

\section{Tiago Carvalho \\ University of Minho \\ School of Engineering, Centro Algoritmi \\ Department of Production and Systems \\ Campus Azurem, 4800-058 Guimaraes, Portugal \\ e-mail: tiagoandrecarvalho@gmail.com}

\section{Vera Silva \\ University of Minho \\ School of Engineering, Centro Algoritmi \\ Department of Production and Systems \\ Campus Azurem, 4800-058 Guimaraes, Portugal \\ e-mail: vemosilva@hotmail.com}

\section{Rui M. Lima}

University of Minho

School of Engineering, Centro Algoritmi

Department of Production and Systems

Campus Azurem, 4800-058 Guimaraes, Portugal

e-mail: rml@dps.uminho.pt 